\title{
The effect of stem growth habit on single seed weight and seed uniformity in soybean (Glycine max (L.) Merrill)
}

\author{
Shin Kato*1), Takashi Sayama ${ }^{2)}$, Masao Ishimoto ${ }^{3)}$, Setsuzo Yumoto ${ }^{3)}$, Akio Kikuchi ${ }^{1)}$ and Takeshi Nishio ${ }^{4)}$ \\ 1) Tohoku Agricultural Research Center, National Agriculture and Food Research Organization (NARO), 297 Uenodai, Kariwano, \\ Daisen, Akita 019-2112, Japan \\ 2) Western Region Agricultural Research Center, NARO, 1-3-1 Senyuu, Zentsuji, Kagawa 765-8508, Japan \\ 3) Institute of Crop Science, NARO, 2-1-2 Kannondai, Tsukuba, Ibaraki 305-8602, Japan \\ 4) Graduate School of Agricultural Science, Tohoku University, 1-1 Tsutsumidori, Amamiyamachi, Aoba, Sendai, Miyagi 981-8555, \\ Japan
}

\begin{abstract}
The timing of flower formation and length of the seed-filling period of indeterminate growth soybean varieties vary more than those of determinate varieties (Glycine max (L.) Merrill). These variations have been hypothesized to affect single seed weight and its uniformity which determine the processing quality of soybean used in foods. We derived near isogenic lines (NILs) with different growth characteristics from an indeterminate line (donor parent) and three determinate lines with heavy seeds (recurrent parents), and evaluated the effects of growth habit on seed weight and its uniformity. Each NIL population consisting of five indeterminate and five determinate $\mathrm{BC}_{4} \mathrm{~F}_{4}$ lines tested at two locations in two different years with two replications. Split-plot analysis of variance, with main-plot and sub-plot being cross combination and growth habit, respectively, showed that indeterminate varieties had slightly heavier seeds than determinate varieties and that there was no significant difference in uniformity of single seed weights. The effects of growth habit on seed uniformity was related to genetic background, but differences between the two growth characteristics were less than the differences among genetic background. This indicates that indeterminate growth habit did not much influence seed weight or its uniformity.
\end{abstract}

Key Words: near isogenic line, seed uniformity, single seed weight, soybean, stem growth habit.

\section{Introduction}

Soybean (Glycine $\max (\mathrm{L})$. Merr.) is an important legume crop used in processed foods and animal feed worldwide. Improvement in yield is one of the most important objectives of soybean breeding programs. Stem growth habit is an important trait affecting seed yield (Cober and Tanner 1995, Ouattara and Weaver 1994) and is classified into three types: indeterminate, semi-determinate, and determinate growth habit, based on the growth dynamics of the main stem after flowering (Bernard 1972). Stem growth habit is controlled by the combination of two genes, Dt1 and Dt2 (Bernard 1972). The Dt1 gene has been demonstrated to be the TERMINAL FLOWER1 (GmTFL1) gene on chromosome 19, determined via transformation and virus-induced

Communicated by Toyoaki Anai

Received November 15, 2017. Accepted March 12, 2018.

First Published Online in J-STAGE on June 29, 2018.

*Corresponding author (e-mail: katoshin@affrc.go.jp) gene silencing experiments (Liu et al. 2010, Tian et al. 2010). The GmTFL1 transcript accumulates in the shoot apical meristem during early vegetative growth in both the determinate and indeterminate lines, but thereafter is abruptly lost in the determinate line (Liu et al. 2010). Cultivating recombinant inbred line populations developed from crosses between indeterminate and determinate in northern and southern parts of Japan, Kato et al. (2015) showed that yields of early maturity indeterminate lines were higher than those of determinate ones in the northern part of Japan.

Single seed weight (SSW) is one of the crucial traits affecting the processing quality of soybean used in foods and it determines a soybean's commercial value. Varieties with large SSW ( $>300 \mathrm{mg}$ per seed) have been used for boiled, green soybeans (edamame) and boiled beans, while varieties with small SSW ( $<150 \mathrm{mg}$ per seed) have been used for fermented, steamed beans, called 'natto'. Furthermore, SSW is an important trait for processed tofu. It has been shown that SSW is positively correlated with fresh tofu yield because the ratio of insoluble seed coat to seed volume 
of heavy-seeded varieties is lower than the ratio determined from light-seeded varieties (Cui et al. 2004). Therefore, in Japan, China, and North America, SSW has been one of the most important commercial traits associated with soybean production for indigenous consumption and/or for export. As a consequence, many soybeans of both heavy- and light-seeded varieties have been developed (Cui et al. 2004). Therefore, soybean genetic resources show a wide variation in SSW, which ranges from less than $50 \mathrm{mg}$ to more than $750 \mathrm{mg}$ (Kaga et al. 2012). In addition, the uniformity of SSW is also a commercially important trait (Yoshida 1987). In boiled beans, the uniformity of SSW directly affects the aesthetic quality of the end product, while in tofu, miso (a fermented and steamed bean paste), and natto, this trait affects the uniformity of soaking time, steaming, and fermentation. In Japan, the prices of soybean products vary depending on the grade based on the aesthetic quality and seed uniformity is one of the important factors affecting this quality. Therefore, seed uniformity has been considered as a high priority trait in Japanese soybean breeding programs (Yoshida 1987). In indeterminate soybean varieties, variations in the timing of flower formation and length of the seed-filling period depends more on flower node position than determinate-growth habit (Nagata 1967); these variations are presumed to affect SSW and its uniformity. Bernard (1972) developed near isogenic lines (NILs) with various stem growth habits by introducing the $d t 1$ gene to varieties with medium-weight soybeans seeds (150-300 mg per seed) grown in the United States (US) (i.e., 'Harosoy' and 'Clark') by backcrossing, demonstrating that there is no significant difference in SSWs between indeterminate and determinate lines. Similarly, using the same NILs, Yoshida (1987) showed that there was no significant difference in uniformity of SSW between indeterminate and determinate growth characteristics. However, it is not known whether similar results could be obtained if indeterminate traits were introduced into determinate varieties with heavy seeds. It has been known that the seed-filling periods of late-blooming flowers are shorter than those of earlyblooming ones, and that seed-filling speed in late-blooming flowers is higher than that in early-blooming ones (Gbikpi and Grookston 1981). However, when introducing indeterminate growth habit into determinate varieties with heavy seeds, it is possible that an unattainable rapid seed filling rate is required for forming large seeds in late-blooming flowers due to the limited time available for seed filling before senescence, and that average single seed weight and seed uniformity becomes lighter and worse with some seeds in late-blooming flowers failing to become large enough, respectively.

There are concerns about some agricultural traits (e.g., time to maturation and lodging resistance) when considering whether to use indeterminate varieties in areas where determinate varieties have been exclusively cultivated. Maturation may take longer and lodging may be more severe in indeterminate NILs than in determinate NILs. This differ- ence may be due to the longer main stem length and more numerous main stem nodes in indeterminate varieties (Bernard 1972, Cober and Morrison 2010). In addition, when Ouattara and Weaver $(1994,1995)$ developed 23 pairs of stem-growth-habit NILs from the crosses between indeterminate and determinate varieties, they showed that the effects of stem growth habit on agricultural characteristics (e.g., yield, yield components, and the number of branches grown), varied depending on the genetic background and growing environment of the crosses. Furthermore, recent analyses of allelic diversity at molecular marker loci revealed that genetic resources from soybean gene pools in Japan differ in genetic background from the varieties cultivated in North America and China (Abe et al. 2003, Hwang et al. 2008, Kaga et al. 2012, Ude et al. 2003, Zhou et al. 2000). Therefore, the effects of stem growth habit on soybean traits should be evaluated on each genetic background and growing environment.

Because indeterminate soybean varieties are rarely cultivated in Japan, research is limited on the effects that indeterminate varieties have on agricultural characteristics under field conditions in Japan and/or their genetic backgrounds. In this study, we developed stem-growth-habit NILs by introducing indeterminate traits into determinate varieties that have heavy seeds, and evaluated the influence of the introduced traits relative to stem growth patterns on SSW, uniformity of SSW, and other agronomic characteristics.

\section{Materials and Methods}

\section{Plant materials}

Growth habit NILs were developed by backcrossing four times. We used an indeterminate breeding line (donor parent) with medium-weight seeds ('Y1312-2') and three determinate breeding lines (recurrent parents) with heavyweight seeds (i.e., 'Tohoku 160', 'Tohoku 162', and 'Tohoku 164'). Maturation times for the recurrent parents varied: 'Tohoku 160' (late), 'Tohoku 162' (middle), and 'Tohoku 164' (middle). 'Tohoku 160' and 'Tohoku 164' varieties were registered as 'Satonohohoemi' and 'Akimiyabi', respectively (Kato et al. 2014, Kikuchi et al. 2011). The donor parent, 'Y1312-2', is a breeding line developed from a cross between the Japanese determinate line 'Tohoku 140' and the US indeterminate variety 'Olympus' (Diers et al. 1998).

The three recurrent parents $(d t 1 / d t 1)$ were crossed with 'Y1312-2' (Dt1/Dt1) in 2008, and backcrosses were repeated four times from 2009 to 2010 at the Kariwano Branch of the Daisen Research Station of Tohoku Agricultural Research Center, NARO (hereafter, Kariwano Branch). When the backcrosses were repeated, DNA markers near the Dt1 locus were genotyped, and Dt1/dt1 plants were selected as pollen parents. In each backcross combination, one Dt1/dt1 $\mathrm{BC}_{4} \mathrm{~F}_{1}$ plant was grown in 2011, and then in 2012, five Dt1/ $D t 1$ and five $d t 1 / d t 1$ plants were selected (based on the alleles of DNA markers) from a $\mathrm{BC}_{4} \mathrm{~F}_{2}$ population. In 2013, 
the five $D t 1 / D t 1$ and five $d t 1 / d t 1 \quad \mathrm{BC}_{4} \mathrm{~F}_{3}$ lines were cultivated in the field and the consistency between the phenotype and genotype of $D t 1$ of each line was confirmed by observing the growth of their main stem after flowering. $\mathrm{BC}_{4} \mathrm{~F}_{4}$ lines, which were obtained by bulk harvesting seeds of $\mathrm{BC}_{4} \mathrm{~F}_{3}$ lines, were used as the growth habit NILs in this study.

\section{Maker-assisted selection}

The physical map positions of DNA markers and genes were based on the soybean genome database Wm82.a1 (Schmutz et al. 2010). Since it was difficult to select the Dt1/dt1 plants morphologically before flowering, SSR markers located near the Dt1 gene were genotyped (i.e., GmTFL1 (Glyma19g37890, 44,979-44,981 Kb on chromosome 19), which is Sat_286 (44,978 Kb on chromosome 19) and Sat $184(45,179 \mathrm{~Kb})$ ) (Liu et al. 2010, Tian et al. 2010). In the process of selecting $D t 1 / D t 1$ and $d t 1 / d t 1$ plants from the $\mathrm{BC}_{4} \mathrm{~F}_{2}$ population, we used the DNA marker 'Dt1Int', which was designed using the polymorphism within the GmTFL1 gene (Kato et al. 2015).

Because the major maturity gene, E3 (GmPhyA3, Glyma19g41210, 47,512-47,519 Kb on chromosome 19), is located near GmTFL1 on the same chromosome, plants which were heterozygous at $D t 1$ (and had the alleles of the recurrent parents at the $E 3$ locus) were selected as pollen parents. Thus, the linkage between $D t 1$ and $E 3$ were broken. The SSR markers near the E3 gene (i.e., E3at-U113k, FT3SSR4, FT3SSR1dom, and FT3SSR3) were used for genotyping of E3 (Yamada et al. 2012). Genotypes of 'Dt1Int' were analyzed by using $7.5 \%$ polyacrylamide gel electrophoresis, while the other markers were genotyped with a DNA sequencer (3730 Genetic Analyzer DNA sequencer; Applied Biosystems, CA, US), according to Sayama et al. (2011).

Because there are six alleles at the GmTFL1 locus (i.e., GmTfl1-a (Dt1), GmTfl1-b (Dt1), Gmtfl1-ta (dt1), Gmtfl1-ab (dt1), Gmtfl1-bb (dt1), and Gmtfl1-tb (dt1)) (Tian et al. 2010), the alleles of GmTFL1 used for the parents ('Tohoku 160', 'Tohoku 162', 'Tohoku 164', and 'Y1312-2') were identified by sequencing this gene before our marker analysis for GmTFL1, in accordance with Tian et al. (2010). Furthermore, four major maturity genes (i.e., E1,E2, E3, and E4) were genotyped using seven DNA markers developed by Tsubokura et al. (2014) with some check varieties (i.e., 'Enrei' (JP28862, E1/e2-ns/e3-tr/E4), 'Harosoy-e4' (PI591435, e1-as/e2-ns/E3-Ha/e4-SORE1), 'Fukuyutaka' (JP29668, E1/E2-dl/E3-Mi/E4), 'Toyosuzu' (JP27540, e1$n l / e 2-n s / E 3-M i / E 4)$, 'Sakamotowase' (JP27450, e1-fs/e2-ns/ e3-tr/E4), 'Harosoy' (PI548573, e1-as/e2-ns/E3-Ha/E4), 'Moshidou Gong 503' (JP27603, e1-as/E2-in/e3-Mo/E4)) (JP, accession number of NARO Genebank in Japan; PI, accession number from the USDA-ARS National Plant Germplasm System in US).

\section{Evaluation of agricultural characteristics}

Agricultural characteristics of the NILs were evaluated at
Uenodai $\left(39^{\circ} 32^{\prime} \mathrm{N}, 140^{\circ} 22^{\prime} \mathrm{E}\right)$ and Ishinazaka $\left(39^{\circ} 32^{\prime} \mathrm{N}\right.$, $140^{\circ} 23^{\prime} \mathrm{E}$ ) of the Kariwano Branch. Soils in both experimental fields are andosols. The field at Uenodai was fertilized with $24 \mathrm{~kg} \mathrm{ha}^{-1}$ of $\mathrm{N}, 160 \mathrm{~kg} \mathrm{ha}^{-1}$ of $\mathrm{P}_{2} \mathrm{O}_{5}, 80 \mathrm{~kg} \mathrm{ha}^{-1}$ of $\mathrm{K}_{2} \mathrm{O}$, and $20 \mathrm{tha}^{-1}$ of compost before sowing, whereas the field at Ishinazaka was fertilized with $24 \mathrm{~kg} \mathrm{ha}^{-1}$ of N, $120 \mathrm{~kg} \mathrm{ha}^{-1}$ of $\mathrm{P}_{2} \mathrm{O}_{5}, 80 \mathrm{~kg} \mathrm{ha}^{-1}$ of $\mathrm{K}_{2} \mathrm{O}$, and received no compost before sowing. Each line was planted in plots 1.2$1.6 \mathrm{~m}$ in length with a row spacing of $0.75 \mathrm{~m}$ and $0.12 \mathrm{~m}$ plant separations within each row, except at the Uenodai field in 2014 (0.16 m plant separation within each row). Experiments in all growing environments consisted of three cross combinations (main-plot) and two stem growth habits (sub-plot) in split-plot design with two replications. The planting dates of the fields varied by year: Uenodai (27 May 2014 and 23 May 2016) and Ishinazaka (21 May 2014 and 19 May 2016).

We measured the following fifteen characteristics in our soybean varieties: flowering time, seed-filling period, maturation time, lodging, main stem length, lowest pod height, number of main stem nodes, number of main stem branches, number of pods per plant, number of seeds per pod, seed yield per plant, SSW, coefficient of variation of SSW (SWCV), protein content, and oil content. Flowering time, maturation time, and seed-filling period were defined as the number of days from sowing to flowering, sowing to maturation, and flowering to maturation, respectively. Lodging score was visually recorded in each plot as 0 (no lodging) to 5 (completely lodged) by intervals of one based on the number of lodged plants and its degree of lodging according to Kato et al. (2016). Three plants were selected randomly in each plot to measure main stem length, lowest pod height, number of main stem nodes, number of main stem branches, number of pods per plant, and number of seeds per pod. Plants were threshed individually and SSW and SWCV were measured by weighing a single seed (with a Quintix213-1SJP electronic force balance, Sartorius, Göttingen, Germany) from 100 seeds randomly selected from each plant. The above metrics for the three selected plants from each plot were averaged and the means were assigned to the appropriate plots. The other plants in each plot (excluding the two plants at the both ends of every row) were threshed in bulk and seed yield was calculated by dividing total seed weight by the number of harvested plants (Seed yields for the three individually threshed plants (above) were included in the yield of the plants threshed in bulk). Protein and oil content were determined for the seed mass threshed using a near-infrared spectrophotometer (Infratec 1241 Grain Analyzer; FOSS Hillerød, Denmark). Moisture content was determined with a grain moisture tester (PM830-2; Kett Electric Laboratory, Tokyo, Japan) and seed yield per plant was adjusted to reflect a water contents of $15 \%$.

Split-plot analysis of variance (ANOVA) was carried out with SAS (SAS, Cary, NC, USA). Cross combination and stem growth habit were considered main-plot and sub-plot, 
respectively, and location and year were considered fixed effects. Where there was a significant combination by stem growth habit interaction, the comparisons between stem growth habits in each cross combination was carried out with three-way ANOVA with EZR (Kanda 2013), which is a graphical user interface for R (http://www.r-project.org). A $P$ value of $<0.05$ was considered significant.

\section{Results}

Genotyping of Dt1 and the four major maturity genes of the recurrent and donor parents

The $D t 1$ alleles of the recurrent and donor parents were identified by nucleotide sequencing of the GmTFL1 locus from -740 to +1440 (the adenine of the start codon was numbered +1). The GmTFL1 sequence of 'Y1312-2' was identical to that of GmTfl1-a (Dt1), while the GmTFL1 sequences of all three recurrent parents were identical to the Gmtfl1-ab (dt1) sequence. The Gmtfll-ab allele has a nonsynonymous substitution from arginine (Dt1) to tryptophan $(d t 1)$ at 166-th amino acid residue affecting the function of TFL1 protein (Tian et al. 2010). Because there was a 6-bp length polymorphism between the GmTfl1- $a$ and Gmtfl-ab sequences in the 1st intron, the GmTFL1 genotypes of the recurrent and donor parents were analyzed by distinguishing this polymorphism length of PCR products amplified by a primer pair of Dt1Int. The PCR products of recurrent parents produced bands of $123 \mathrm{bp}$, while the PCR products of the donor parent produced bands of $129 \mathrm{bp}$. The genotyping of the seven DNA markers for the four major maturity genes revealed that the 'Y1312-2' variety was E1/e2-ns/e3-tr/E4, while all the three recurrent parents were E1/e2-ns/E3-Mi E4.

\section{Development of the stem growth habit NILs}

The recurrent parents and 'Y1312-2' were crossed in 2008. Backcrosses to the recurrent parents were repeated four times with marker-assisted selection for the $D t 1$ and $E 3$ genes. For each backcrossed combination, one $\mathrm{BC}_{4} \mathrm{~F}_{1}$ plant, whose linkage between $D t 1$ and $E 3$ was broken, was grown in 2011. In 2012, $60 \mathrm{BC}_{4} \mathrm{~F}_{2}$ seeds were planted, and then, Dt1 genotyping of $38-48$ healthy $\mathrm{BC}_{4} \mathrm{~F}_{2}$ plants in each cross combination showed that there were $15 d t 1$ homozygotes,
14 Dt1 homozygotes, and 19 heterozygotes in NILs developed using 'Tohoku 160 ' as a recurrent parent (hereafter named, BC/T160): $13 d t 1$ homozygotes, 10 Dt1 homozygotes, and 17 heterozygotes in NILs using 'Tohoku 162' as a recurrent parent (hereafter, BC/T162); and, $10 d t 1$ homozygotes, 13 Dt1 homozygotes, and 15 heterozygotes in NILs using 'Tohoku 164' as a recurrent parent (hereafter, $\mathrm{BC} / \mathrm{T} 164)$. In 2013, $10 \mathrm{BC}_{4} \mathrm{~F}_{3}$ lines were cultivated in the field; these lines were derived from five indeterminate and five determinate plants in $\mathrm{BC}_{4} \mathrm{~F}_{2}$ for each cross combination. The consistency between phenotype and genotype of $D t 1$ was confirmed by observing the growth of the main stem after flowering. In addition, the lines did not segregate for flowering or maturity time, or main stem length. In 2014, $\mathrm{BC}_{4} \mathrm{~F}_{4}$ lines were obtained by harvesting each $\mathrm{BC}_{4} \mathrm{~F}_{3}$ line in bulk.

\section{The effect of stem growth habit on SSW and SWCV}

Comparison of stem growth habit (S) demonstrated that SSW values of indeterminate lines were slightly heavier compared to determinate lines, and that there was no significant difference in SWCV (Tables 1, 2). The effects of cross combination (C) were significant for SSW and SWCV, while the effect of location (L) and year (Y) was significant only for SSW.

There were significant interaction effects for $\mathrm{S} \times \mathrm{C}$ in SWCV, but no significant interaction effect in SSW (Table 2). The comparison of mean values between growth habits for SWCV in each cross combination (using factor S) demonstrated that the effects of stem growth habit on SWCV depends on genetic background (Fig. 1). However, the mean squares of the interaction for SWCV between stem growth habit and cross combination were 3.5 times lower than that of cross combination effects (Table 2).

\section{The effect of stem growth habit on the other agricultural characteristics}

There were significantly more seeds per pod in indeterminate lines than in determinate lines, whereas there was no significant difference between seed yield and the number of pods (Tables 1, 2). Flowering time, seed-filling period, and time to maturation of indeterminate lines was 0.8 days, 0.5 days, and 1.2 days longer than those parameters in

Table 1. Mean values in each level for yield, yield components, and traits related to seeds of near isogenic lines with different growth habits

\begin{tabular}{|c|c|c|c|c|c|c|c|c|}
\hline Factor & Level & $\begin{array}{l}\text { Number of } \\
\text { pods }\end{array}$ & $\begin{array}{c}\text { Number of } \\
\text { seeds per pod }\end{array}$ & $\begin{array}{l}\text { Seed yield } \\
\text { (g/plant) }\end{array}$ & $\begin{array}{l}\text { SSW } \\
(\mathrm{mg})\end{array}$ & SWCV & $\begin{array}{c}\text { Protein } \\
\text { content }(\%)\end{array}$ & $\begin{array}{l}\text { Oil content } \\
(\%)\end{array}$ \\
\hline \multirow[t]{2}{*}{ Stem growth habit (S) } & Determinate & 66.5 & 2.03 & 45.9 & 347 & 0.110 & 43.1 & 19.8 \\
\hline & Indeterminate & 65.4 & 2.10 & 46.0 & 352 & 0.110 & 42.8 & 19.8 \\
\hline \multirow{3}{*}{ Cross combination (C) } & BC/Tohoku162 & 70.8 & 1.99 & 46.1 & 334 & 0.115 & 41.6 & 20.7 \\
\hline & BC/Tohoku164 & 66.2 & 2.08 & 45.2 & 344 & 0.113 & 43.6 & 18.3 \\
\hline & BC/Tohoku160 & 61.0 & 2.11 & 46.7 & 370 & 0.102 & 43.6 & 20.5 \\
\hline \multirow[t]{2}{*}{ Location (L) } & Ishinazaka & 61.3 & 2.06 & 41.2 & 340 & 0.114 & 42.6 & 20.0 \\
\hline & Uenodai & 70.6 & 2.06 & 50.8 & 359 & 0.106 & 43.2 & 19.6 \\
\hline \multirow[t]{2}{*}{ Year (Y) } & 2014 & 72.3 & 2.02 & 45.7 & 362 & 0.110 & 43.1 & 18.9 \\
\hline & 2016 & 59.6 & 2.10 & 46.2 & 337 & 0.110 & 42.8 & 20.7 \\
\hline
\end{tabular}


Table 2. Analysis of variance for yield, yield components, and traits related to seeds of near isogenic lines with different growth habits

\begin{tabular}{|c|c|c|c|c|c|c|c|c|}
\hline \multirow[b]{2}{*}{ Sources of variation } & \multirow{2}{*}{$\begin{array}{c}\text { Degree } \\
\text { of } \\
\text { freedom }\end{array}$} & \multicolumn{7}{|c|}{ Mean of square } \\
\hline & & $\begin{array}{c}\text { Number of } \\
\text { pods }\end{array}$ & $\begin{array}{c}\text { Number of } \\
\text { seeds per pod }\end{array}$ & Seed yield & SSW & SWCV & $\begin{array}{l}\text { Protein } \\
\text { content }\end{array}$ & $\begin{array}{c}\text { Oil } \\
\text { content }\end{array}$ \\
\hline Location (L) & 1 & $5156.9 * a$ & $0.0018 \mathrm{NS}$ & $5508.5 *$ & $20314 *$ & $0.00400 \mathrm{NS}$ & $21.2 \mathrm{NS}$ & $9.7 *$ \\
\hline Year $(\mathrm{Y})$ & 1 & $9744.8 * *$ & $0.3383 * * *$ & $15.7 \mathrm{NS}$ & $38964 *$ & $0.00001 \mathrm{NS}$ & 4.6 NS & $191.7 * *$ \\
\hline $\mathrm{L} \times \mathrm{Y}$ & 1 & $1068.9 \mathrm{NS}$ & $0.0002 \mathrm{NS}$ & $1810.6 \mathrm{NS}$ & $2344 \mathrm{NS}$ & $0.00008 \mathrm{NS}$ & $1.0 \mathrm{NS}$ & $1.6 \mathrm{NS}$ \\
\hline Cross combination (C) & 2 & $1952.7 * *$ & $0.3042 * * *$ & $45.3 \mathrm{NS}$ & $27749 * * *$ & $0.00394 * * *$ & $110.4 * * *$ & $141.6 * * *$ \\
\hline Pooled error a & 8 & 104.7 & 0.0030 & 41.4 & 710 & 0.00018 & 3.0 & 0.8 \\
\hline Stem growth habit (S) & 1 & $67.5 \mathrm{NS}$ & $0.3132 * * *$ & $0.4 \mathrm{NS}$ & $1251 *$ & $0.00002 \mathrm{NS}$ & $6.6 *$ & $0.0 \mathrm{NS}$ \\
\hline $\mathrm{S} \times \mathrm{C}$ & 2 & $3.0 \mathrm{NS}$ & $0.0320 * *$ & 7.8 NS & $87 \mathrm{NS}$ & $0.00113 * *$ & $3.6 \mathrm{NS}$ & $0.4 \mathrm{NS}$ \\
\hline Pooled error $b$ & 12 & 104.0 & 0.0029 & 35.8 & 134 & 0.00013 & 1.0 & 0.2 \\
\hline
\end{tabular}

$a *, * *$, and $* * *$ are significant at $5 \%, 1 \%$, and $0.1 \%$ probability levels, respectively. NS: not significant.

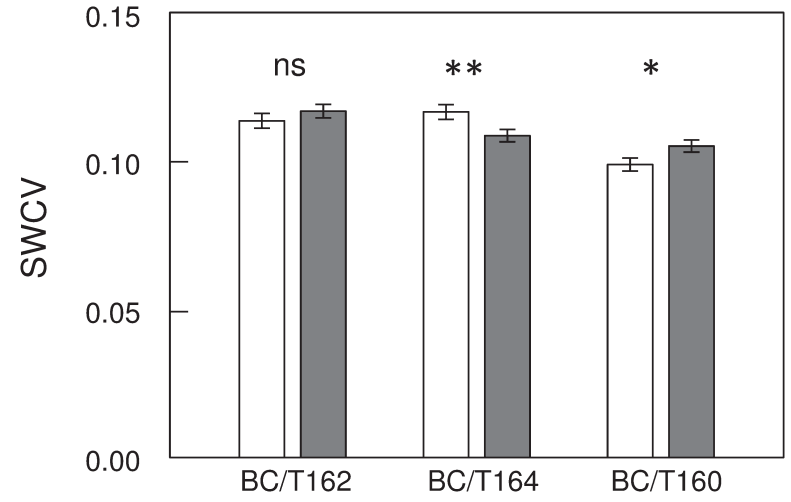

Fig. 1. Comparison of SWCV between indeterminate and determinate lines. The comparison of coefficient of variation of SSW (SWCV) by cross combination between determinate and indeterminate growth habit lines is shown. White and gray bars indicate the average score of determinate and indeterminate lines, respectively. Error bars represent standard errors.

determinate lines, respectively; except for seed-filling period, these differences were significant (Tables 3, 4). The number of main stem nodes of indeterminate lines was 1.3 times more than in determinate lines, while main stem length was 1.6 times longer (Table 3 ). The mean number of branches in indeterminate lines was 0.7 greater than in determinate lines (Table 3). The lowest pod height of indeterminate lines was $3.1 \mathrm{~cm}$ higher, while mean lodging score of indeterminate lines scored 1.1 higher than determinate lines (Table 3). The protein content of indeterminate lines was $0.3 \%$ lower than the protein content in determinate lines, while there was no difference in oil content (Table 1).

\section{Discussion}

Timing of flower formation and the length of seed-filling period in indeterminate varieties tend to vary more than those of determinate varieties, depending on the flower node positions (Nagata 1967, Yoshida 1987). Variations in timing and duration of seed-filling period are presumed to affect SSW and its uniformity. Although Bernard (1972) and Yoshida (1987) reported that there is no significant difference in SSW and seed uniformity between stem growth habit of NILs with normal SSW, it is unclear what the effect would be on these traits if indeterminate traits were introduced into determinate varieties with heavier seeds. It is possible that an unattainable rapid seed filling rate is required for forming large seeds in late-blooming flowers due to the limited time available for seed filling before senescence. In this study, we developed NILs with genes controlling stem growth habit by introducing indeterminate traits into determinate varieties that have large SSWs, and evaluated the influence of stem growth habit on SSW and SWCV. The cultivation of NILs with a variety of stem

Table 3. Mean values in each level for duration between growth stages and morphological characteristics of near isogenic lines with different growth habits

\begin{tabular}{|c|c|c|c|c|c|c|c|c|c|}
\hline Factor & Level & $\begin{array}{l}\text { Flowering } \\
\text { time }\end{array}$ & $\begin{array}{l}\text { Seed-filling } \\
\text { period }\end{array}$ & $\begin{array}{l}\text { Maturing } \\
\text { time }\end{array}$ & $\begin{array}{l}\text { Main stem } \\
\text { length }(\mathrm{cm})\end{array}$ & $\begin{array}{c}\text { Number of } \\
\text { main stem } \\
\text { nodes }\end{array}$ & $\begin{array}{l}\text { Lodging } \\
\quad(0-5)\end{array}$ & $\begin{array}{l}\text { Number of } \\
\text { branches }\end{array}$ & $\begin{array}{l}\text { Lowest pod } \\
\text { height }(\mathrm{cm})\end{array}$ \\
\hline \multirow[t]{2}{*}{ Stem growth habit $(\mathrm{S})$} & Determinate & 65.0 & 76.9 & 142.0 & 69 & 16.2 & 1.3 & 4.9 & 17.0 \\
\hline & Indeterminate & 65.8 & 77.4 & 143.2 & 110 & 21.8 & 2.4 & 5.6 & 20.1 \\
\hline \multirow[t]{3}{*}{ Cross combination $(\mathrm{C})$} & BC/Tohoku162 & 61.7 & 70.8 & 132.4 & 84 & 17.8 & 2.1 & 5.0 & 14.6 \\
\hline & BC/Tohoku164 & 66.5 & 77.1 & 143.6 & 90 & 20.1 & 1.4 & 5.0 & 17.6 \\
\hline & BC/Tohoku160 & 68.2 & 83.7 & 151.8 & 95 & 19.2 & 2.0 & 5.8 & 23.4 \\
\hline \multirow[t]{2}{*}{ Location (L) } & Ishinazaka & 66.8 & 77.4 & 144.2 & 88 & 18.9 & 1.8 & 4.8 & 18.0 \\
\hline & Uenodai & 64.0 & 77.0 & 141.0 & 91 & 19.1 & 1.9 & 5.7 & 19.1 \\
\hline \multirow[t]{2}{*}{ Year (Y) } & 2014 & 62.0 & 81.4 & 143.3 & 98 & 19.7 & 1.9 & 5.9 & 18.3 \\
\hline & 2016 & 68.9 & 73.0 & 141.9 & 81 & 18.4 & 1.8 & 4.7 & 18.8 \\
\hline
\end{tabular}


Table 4. Analysis of variance for duration between growth stages and morphological characteristics of near isogenic lines with different growth habits

\begin{tabular}{|c|c|c|c|c|c|c|c|c|c|}
\hline \multirow[b]{2}{*}{$\begin{array}{l}\text { Sources of } \\
\text { variation }\end{array}$} & \multirow[b]{2}{*}{$\begin{array}{c}\text { Degree } \\
\text { of } \\
\text { freedom }\end{array}$} & \multicolumn{8}{|c|}{ Mean of square } \\
\hline & & $\begin{array}{l}\text { Flowering } \\
\text { time }\end{array}$ & $\begin{array}{l}\text { Seed-filling } \\
\text { period }\end{array}$ & $\begin{array}{l}\text { Maturation } \\
\text { time }\end{array}$ & $\begin{array}{l}\text { Main stem } \\
\text { length }\end{array}$ & $\begin{array}{c}\text { Number of } \\
\text { main stem } \\
\text { nodes }\end{array}$ & Lodging & $\begin{array}{c}\text { Number of } \\
\text { branches }\end{array}$ & $\begin{array}{c}\text { Lowest pod } \\
\text { height }\end{array}$ \\
\hline $\mathrm{L}$ & 1 & $467.6 * * *$ a & $7.7 \mathrm{NS}$ & $595.4 * *$ & $459.5 \mathrm{NS}$ & $2.8 \mathrm{NS}$ & $2.0 \mathrm{NS}$ & $46.0 * *$ & $64.7 \mathrm{NS}$ \\
\hline $\mathrm{Y}$ & 1 & $2863.5 * * *$ & $4208.4 * * *$ & $129.1 *$ & $17973.0 * * *$ & $110.4 * * *$ & $1.7 \mathrm{NS}$ & $85.8 * *$ & $10.2 \mathrm{NS}$ \\
\hline $\mathrm{L} \times \mathrm{Y}$ & 1 & $22.2 *$ & $37.6 \mathrm{NS}$ & $117.6 *$ & $44.5 \mathrm{NS}$ & $1.1 \mathrm{NS}$ & $0.3 \mathrm{NS}$ & $0.4 \mathrm{NS}$ & $21.7 \mathrm{NS}$ \\
\hline $\mathrm{C}$ & 2 & $912.8 * * *$ & $3335.0 * * *$ & $7602.7 * * *$ & $2196.6 * *$ & $107.6 * * *$ & $13.9 *$ & $16.1 * * *$ & $1594.5 * * *$ \\
\hline Pooled error a & 8 & 2.6 & 30.2 & 27.2 & 124.5 & 1.0 & 2.2 & 0.6 & 8.2 \\
\hline S & 1 & $39.2 * * *$ & $12.6 \mathrm{NS}$ & $96.3 * *$ & $102709.3 * * *$ & $1870.4 * * *$ & $84.0 * * *$ & $34.9 * * *$ & $564.3 * * *$ \\
\hline $\mathrm{S} \times \mathrm{C}$ & 2 & $8.1 * *$ & $5.0 \mathrm{NS}$ & $19.7 \mathrm{NS}$ & $122.9 *$ & $13.4 * * *$ & $0.4 \mathrm{NS}$ & $1.4 \mathrm{NS}$ & $1.0 \mathrm{NS}$ \\
\hline Pooled error $b$ & 12 & 0.9 & 4.7 & 5.5 & 24.1 & 0.8 & 0.4 & 0.5 & 7.4 \\
\hline
\end{tabular}

a $* * *$, and $* * *$ are significant at $5 \%, 1 \%$, and $0.1 \%$ probability levels, respectively. NS: not significant.

growth habits, from multiple genetic backgrounds and grown under two different growing environments, demonstrates that there is no significant difference between the indeterminate and determinate lines in SWCV, and that indeterminate lines produce slightly heavier seeds than do determinate lines. On the other hand, the mean squares of the cross combination effects for SSW and SWCV were 22 and 197 times higher than those of stem termination effects, respectively (Table 2). These results show that differences between genetic backgrounds were more than the differences between the two growth habit characteristics. For example, seed weight uniformity of NILs in soybeans developed using 'Tohoku 160' as the recurrent parent was higher than any of the other NILs we developed, regardless of stem growth habit. This suggests that some control of seed uniformity works independently of stem growth habit. In determinate soybeans, pod formation ratio of early blooming flowers tends to be higher than that of later ones (Hayashi 1998, Tajiri and Tateno 1952). In contrast, the ratio of pod formation in indeterminate soybeans is low in flowers that bloom within 10 days after flowering commences, although the ratio of pod formation in the latest-blooming flowers tend to be low in both indeterminate and determinate soybeans (Yoshida 1987). These previous studies demonstrated that the length of flowering is not directly related to time required for seed filling. Saito et al. (1998) and Zheng et al. (2003) also found that there is a lag period between flowering and pod elongation and that the lag period of lateblooming flowers is shorter than the lag period of earlyblooming flowers. The lag period promotes the synchronous development of pods and seeds originating from flowers blooming at different times on the same plant and this duration differs among soybean varieties (Zheng et al. 2003). Therefore, traits for pod setting ratio and duration of lag period other than seed filling speeds, might be more strictly controlled in the 'Tohoku 160' variety. Indeed, we cannot deny the possibility that seeds from the pods on the first to second nodes from the top raceme of indeterminate line may be small by being affected by the considerably short seed filling periods. However, the number of these seeds is few compared to the number of remaining seeds, and, when harvesting all seeds in bulk, these small seeds are not considered to markedly affect seed uniformity strongly. Based on the aforementioned data, we conclude that indeterminate growth habit in soybeans does not much influence the single seed weight or the uniformity of seed weight.

We found significant interaction for seed uniformity between cross combination and stem growth habit. Although we hypothesized that maturations and SSWs were the factors that affect the interaction between seed uniformity and growth habit, consistent tendencies for these interaction among maturations and SSWs were not observed in our results. It is difficult to know what kinds of genetic background have undesirable effects on seed uniformities of indeterminate growth habit from our results. Tests in which seed uniformities are compared between growth habits under more diverse genetic backgrounds are required in order to understand this interaction in detail. However, when comparing the mean squares of cross combination effect with that of the interaction for SWCV between stem growth habit and cross combination, this interaction were relatively low (Table 2). Therefore, although we cannot deny the possibility that the introduction of Dt1 may reduce seed uniformities in some genetic backgrounds, it is considered to be possible to solve this uniformity problem due to the introduction of different growth habits to some extent by using determinate varieties with excellent seed uniformity as recurrent parents. On the other hand, there was no significant interaction for seed weight between cross combination and stem growth habits (Table 2). However, there are some determinate varieties that have particularly heavy seeds (>600 mg), for example 'Tamafukura' and 'Hyokei-kuro 3' (Hirota et al. 2012). The effect of introducing indeterminate growth habit into super-heavy-seeded determinate varieties still needs to be demonstrated.

Although there was no significant difference in seed yield between growth habits (determinate vs. indeterminate), significantly more seeds per pod were produced in indeterminate lines than in determinate lines. This result corresponds to previous studies (Hartung et al. 1981, Hicks et 
al. 1969, Kato et al. 2015). Gm-JAG1, the gene that governs leaf shape $(L n)$, has also been reported to affect the number of seeds per pod and seed weight, and there are more seeds per pod and lighter seeds in soybeans with narrow-leaf alleles $(l n)$ than in homozygotes with broad-leaf alleles $(L n)$ (Dinkins et al. 2002, Jeong et al. 2011, 2012, Sayama et al. 2017). Dt1 and Ln genes commonly influence the number of seeds per pod, although it is impossible to compare the effects of these genes in this study, because leaf shapes of all the recurrent and donor parents were broad type $(L n)$. On the other hand, there is no difference in seed weight between indeterminate and determinate soybean lines. All the above results demonstrate that the relationship between the number of seeds per pod and the other yield components related to stem growth habit differs from those caused by the introduction of the $L n$ gene.

Soybean breeders have long been concerned that indeterminate varieties show a severe lodging and the late maturity (caused by an increase of the main stem length and the number of main stem nodes) associated with continued vegetative growth long after flowering (Bernard 1972, Cober and Morrison 2010, Wilcox and Sediyama 1981). In this study, we found that the introduction of indeterminate traits increased main stem length and main stem nodes, and that the mean rank of lodging scores of indeterminate lines was higher than determinate lines. Since the effects of lodging seriously and negatively impact yield (Noor and Caviness 1980), improvements in lodging resistance will be needed for the introduction of indeterminate traits into determinate varieties. Although, as aforementioned, there was no yield advantage in indeterminate lines, the development of indeterminate varieties with lodging resistance equivalent to that of determinate ones may contribute to breeding new varieties with high yield. On the other hand, although time to maturation in indeterminate varieties was significantly later than in the determinate varieties, the mean squares for the effect for stem growth habits was less than those of location and year (Table 4), and the difference was only one day on an average, which would probably be acceptable.

In our study, there were no differences in oil content between lines, but protein content of indeterminate lines was slightly lower than determinate lines. The influences of introduction of indeterminate traits into determinate varieties for this balance have been reported to change depending on length to maturity, growing conditions, and genetic background of the plants (Bernard 1972, Cober and Morrison 2010, Ouattara and Weaver 1994, Wilcox and Zhang 1997). It is not clear whether the $D t 1$ gene has a pleiotropic effect on protein content or whether the various genes that regulate protein content are located close to the Dt1 gene; however, when introducing indeterminate traits into determinate varieties, the selection of acceptable protein and oil content will be needed in light of the study results described above.

Lowest-pod height is an important trait affecting mechanical harvesting. Planting varieties whose lowest-pod height is high on the plant reduces yield loss when harvest- ing with a combine (Martin and Wilcox 1973). Our results show that the lowest-pod height on a plant of indeterminate varieties was significantly higher than that of determinate varieties, which is consistent with the findings of Ouattara and Weaver (1995).

In conclusion, the introduction of indeterminate traits into determinate varieties with heavy seeds did not much influence seed weight or the variation in seed weight (uniformity), but it did increase the number of main stem nodes, main stem length, and caused more severe lodging. The QTLs related with lodging resistance (Chen et al. 2011, Lee et al. 2015, Yamaguchi et al. 2014) have been reported to be located in a different chromosome region than the $D t 1$ locus. Introduction of these QTLs into soybeans will be required to breed indeterminate varieties.

\section{Acknowledgements}

We thank Dr. Elroy R. Cober, Dr. Bahram Samanfar for critical reading, and Hitoshi Sato, Osamu Fujii, Yuko Sato, Akihiro Takahashi, Kosei Awatsu, Hisaho Takagai and Kenei Takahashi (NARO) for the field management of yield trials. This study was supported by grants from the Ministry of Agriculture, Forestry, and Fisheries of Japan [GenomicsBased Technology for Agricultural Improvement (SFC1001)]. The authors would like to thank Enago (www.enago. jp) for the English language review.

\section{Literature Cited}

Abe, J., D.H.Xu, Y. Suzuki, A. Kanazawa and Y. Shimamoto (2003) Soybean germplasm pools in Asia revealed by nuclear SSRs. Theor. Appl. Genet. 106: 445-453.

Bernard, R.L. (1972) Two genes affecting stem termination in soybeans. Crop Sci. 12: 235-239.

Chen,H., Z.Shan, A.Sha, B.Wu, Z.Yang, S.Chen, R.Zhou and X.Zhou (2011) Quantitative trait loci analysis of stem strength and related traits in soybean. Euphytica 179: 485-497.

Cober, E.R. and J.W. Tanner (1995) Performance of related indeterminate and tall determinate soybean lines in short-season areas. Crop Sci. 35: 361-364.

Cober,E.R. and M.J.Morrison (2010) Regulation of seed yield and agronomic characters by photoperiod sensitivity and growth habit genes in soybean. Theor. Appl. Genet. 120: 1005-1012.

Cui, Z., A.T. James, S. Miyazaki, R.F. Wilson and T.E. Carter Jr. (2004) Breeding specialty soybeans for traditional and new soyfoods. In: Liu, K. (ed.) Soybean as functional foods and ingredient. AOSC press, Champaign, pp. 264-322.

Diers, B.W., T.G.Isleib and C.H.Sneller (1998) Registration of Olympus soybean. Crop Sci. 38: 1400.

Dinkins, R.D., K.R. Keim, L.Farno and L.H.Edwards (2002) Expression of the narrow leaflet gene for yield and agronomic traits in soybean. J. Hered. 93: 346-351.

Gbikpi, P.J. and R.K. Crookston (1981) Effect of flowering date on accumulation of dry matter and protein in soybean seeds. Crop Sci. 21: 652-655.

Hartung, R.C., J.E. Specht and J.H.Williams (1981) Modification of soybean plant architecture by genes for stem growth habit and 
maturity. Crop Sci. 21: 51-56.

Hayashi, T., K. Suzuki and M. Hara (1998) Flowering and podding responses to cool temperature treatment imposed during the flowering period of soybeans (Glycine $\max (\mathrm{L}$.) Merr.). Jpn. J. Crop Sci. 67: 183-186.

Hicks, D.R., J.W.Pendleto, R.L.Bernard and T.J.Johnston (1969) Response of soybean plant types to planting patterns. Agron. J. 61: 290-293.

Hirota,T., T. Sayama, M. Yamasaki, H. Sasama, T. Sugimoto, M. Ishimoto and S. Yoshida (2012) Diversity and population structure of black soybean landraces originating from Tanba and neighboring regions. Breed. Sci. 61: 593-601.

Hwang, T.Y., Y.Nakamoto, I.Kono, H.Enoki, H. Funatsuki, K. Kitamura and M. Ishimoto (2008) Genetic diversity of cultivated and wild soybeans including Japanese elite cultivars as revealed by length polymorphism of SSR markers. Breed. Sci. 58: 315-323.

Jeong, N., J.K. Moon, H.S. Kim, C.G.Kim and S.C. Jeong (2011) Fine genetic mapping of the genomic region controlling leaflet shape and number of seeds per pod in the soybean. Theor. Appl. Genet. 122: 865-874.

Jeong, N., S.J.Suh, M.H.Kim, S.Lee, J.K.Moon, H.S.Kim and S.C. Jeong (2012) $L n$ is a key regulator of leaflet shape and number of seeds per pod in soybean. Plant Cell 24: 4807-4818.

Kaga,A., T.Shimizu, S. Watanabe, Y.Tsubokura, Y.Katayose, K. Harada, D.A. Vaughan and N. Tomooka (2012) Evaluation of soybean germplasm conserved in NIAS genebank and development of mini core collections. Breed. Sci. 61: 566-592.

Kanda, Y. (2013) Investigation of the freely available easy-to-use software 'EZR' for medical statistics. Bone Marrow Transplant. 48: 452-458.

Kato, S., A.Kikuchi, S. Shimamura, Y.Kono, S. Yumoto, Y.Takada, S. Shimada, T. Sakai, H. Shimada, K. Takahashi et al. (2014) A new soybean cultivar, "Akimiyabi," with resistance to soybean mosaic virus and lodging. Bull. Tohoku Agric. Res. Cent. 116: 13-27.

Kato, S., K. Fujii, S. Yumoto, M. Ishimoto, T. Shiraiwa, T. Sayama, A. Kikuchi and T.Nishio (2015) Seed yield and its components of indeterminate and determinate lines in recombinant inbred lines of soybean. Breed. Sci. 65: 154-160.

Kato, S., Y.Takada, S. Shimamura, K. Hirata, T. Sayama, F. TaguchiShiobara, M. Ishimoto, A. Kikuchi and T. Nishio (2016) Transfer of the Rsv3 locus from Harosoy for resistance to soybean mosaic virus strains C and D in Japan. Breed. Sci. 66: 319-327.

Kikuchi,A., Y.Kono, S.Kato, S. Yumoto, Y.Takada, S. Shimada, T. Sakai, H. Shimada, K. Takahashi, T.Adachi et al. (2011) A new soybean cultivar, "Satonohohoemi", with high protein content, lodging resistance, large seed size and good quality. Bull. Tohoku Agric. Res. Cent. 113: 1-15.

Lee, S., T.H.Jun, A.P. Michel and M.A.R. Mian (2015) SNP markers linked to QTL conditioning plant height, lodging, and maturity in soybean. Euphytica 203: 521-532.

Liu, B.H., S. Watanabe, T. Uchiyama, F.J. Kong, A. Kanazawa, Z.J. Xia, A. Nagamatsu, M.Arai, T. Yamada, K. Kitamura et al. (2010) The soybean stem growth habit gene Dt1 is an ortholog of Arabidopsis TERMINAL FLOWER1. Plant Physiol. 153: 198-210.

Martin, R.J. and J.R. Wilcox (1973) Heritability of lowest pod height in soybeans. Crop Sci. 13: 201-203.

Nagata, T. (1967) Studies on the significance of indeterminate growth habit in breeding soybeans. III. Varietal difference in the fruiting process attributable to the habit. a. Maturity and growth of pods and seeds. Japan. J. Breed. 17: 25-32.

Noor, R.B.M. and C.E. Caviness (1980) Influence of lodging on pod distribution and seed yield in soybeans. Agron. J. 72: 904-906.

Ouattara, S. and D.B. Weaver (1994) Effect of growth habit on yield and agronomic characteristics of late-planted soybean. Crop Sci. 34: 870-873.

Ouattara, S. and D.B. Weaver (1995) Effect of growth habit on yield components of late-planted soybean. Crop Sci. 35: 411-415.

Saito, K., S.Isobe and T.Kuroda (1998) Pod elongation and seed growth as influenced by nodal position on stem and raceme order in a determinate type of soybean cultivar. Jpn. J. Crop Sci. 67: $523-528$.

Sayama, T., T.Y.Hwang, K. Komatsu, Y. Takada, M. Takahashi, S. Kato, H. Sasama, A. Higashi, Y. Nakamoto, H. Funatsuki et al. (2011) Development and application of a whole-genome simple sequence repeat panel for high-throughput genotyping in soybean. DNA Res. 18: 107-115.

Sayama, T., T.Tanabata, M.Saruta, T.Yamada, T.Anai, A. Kaga and M. Ishimoto (2017) Confirmation of the pleiotropic control of leaflet shape and number of seeds per pod by the $L n$ gene in induced soybean mutants. Breed. Sci. 67: 363-369.

Schmutz, J., S.B.Cannon, J.Schlueter, J.Ma, T.Mitros, W.Nelson, D.L.Hyten, Q. Song, J.J.Thelen, J. Cheng et al. (2010) Genome sequence of the palaeopolyploid soybean. Nature 463: 178-183.

Tajiri, T. and T. Tateno (1952) An ecological study in soybean. I. Fruiting behavior. Bull. Chugoku Sikoku Natl. Agric. Exp. Stn. 1: 2634.

Tian,Z.X., X.B.Wang, R.Lee, Y.H.Li， J.E.Specht, R.L.Nelson, P.E. McClean, L.J.Qiu and J.X.Ma (2010) Artificial selection for determinate growth habit in soybean. Proc. Natl. Acad. Sci. USA 107: 8563-8568.

Tsubokura,Y., S. Watanabe, Z.Xia, H.Kanamori, H. Yamagata, A.Kaga, Y.Katayose, J.Abe, M. Ishimoto and K. Harada (2014) Natural variation in the genes responsible for maturity loci $E 1, E 2$, $E 3$ and E4 in soybean. Ann. Bot. 113: 429-441.

Ude, G.N., W.J.Kenworthy, J.M. Costa, P.B.Cregan and J.Alvernaz (2003) Genetic diversity of soybean cultivars from China, Japan, North America, and North American ancestral lines determined by amplified fragment length polymorphism. Crop Sci. 43: 18581867.

Wilcox, J.R. and T. Sediyama (1981) Interrelationships among height, lodging and yield in determinate and indeterminate soybeans. Euphytica 30: 323-326.

Wilcox, J.R. and G.D.Zhang (1997) Relationships between seed yield and seed protein in determinate and indeterminate soybean populations. Crop Sci. 37: 361-364.

Yamada,T., M.Hajika, N. Yamada, K. Hirata, A. Okabe, N.Oki, K. Takahashi, K. Seki, K. Okano, Y. Fujita et al. (2012). Effect on flowering and seed yield of dominant alleles at maturity loci E2 and $E 3$ in a Japanese cultivar, Enrei. Breed. Sci. 61: 435-664.

Yamaguchi, N., T. Sayama, H. Yamazaki, T. Miyoshi, M. Ishimoto and H.Funatsuki (2014) Quantitative trait loci associated with lodging tolerance in soybean cultivar 'Toyoharuka'. Breed. Sci. 64: 300308.

Yoshida, K. (1987) Studies on seed size variation in grain legumes. Mem. Grad. Sch. Agric. Hokkaido Univ. 15: 385-434.

Zheng, S.H., A. Maeda and M.Fukuyama (2003) Genotypic and environmental variation of lag period of pod growth in soybean. Plant Prod. Sci. 6: 243-246.

Zhou, X., T.E. Carter, Z.Cui, M. Shoji and J.W.Burton (2000) Genetic base of Japanese soybean cultivars released during 1950-1988. Crop Sci. 40: 1794-1802. 